\title{
Lobectomy of Liver
}

National Cancer Institute

\section{Source}

National Cancer Institute. Lobectomy of Liver. NCI Thesaurus. Code C51555.

Surgical removal of a lobe of the liver. 